\title{
Journal of Cardiovascular Magnetic

\section{058 The extent of tricuspid valve septal displacement adversely affects right ventricular function in Ebstein anomaly: a cardiac MRI study}

\author{
Wyman W Lai*1, Andrew J Powell ${ }^{2}$ and Tal Geva²
}

Address: ${ }^{1}$ Mount Sinai Medical Center, New York, NY, USA and ${ }^{2}$ Children's Hospital Boston, Boston, MA, USA

* Corresponding author

from I th Annual SCMR Scientific Sessions

Los Angeles, CA, USA. I-3 February 2008

Published: 22 October 2008

Journal of Cardiovascular Magnetic Resonance 2008, I0(Suppl I):AI83 doi:I0.II86/I532-429X-I0-SI-AI83

This abstract is available from: http://jcmr-online.com/content//0/SI/AI83

(C) 2008 Lai et al; licensee BioMed Central Ltd.

\section{Introduction}

In normal subjects, LV contraction contributes significantly to RV ejection via ventricular interaction through the septum. In Ebstein anomaly, the functional tricuspid valve is displaced apically resulting in less shared ventricular septal wall. This and other morphologic factors may contribute to the functional abnormalities of both ventricles which have been reported in patients with Ebstein anomaly.

\section{Purpose}

Using MRI, we sought to quantitatively evaluate the impact of various morphologic parameters on $\mathrm{RV}$ and $\mathrm{LV}$ size and function in patients with Ebstein anomaly.

\section{Methods}

The MRI examinations of all patients referred with the diagnosis of Ebstein anomaly from 2000-2007 were reviewed. Inclusion criteria were an apical displacement of the septal leaflet hinge-point of at least $8 \mathrm{~mm} / \mathrm{m}^{2}$ and no prior tricuspid valve surgery. Studies were performed on $1.5 \mathrm{~T}$ clinical scanners. Quantitative data were obtained from gradient echo and steady state free-precession cine images in 4-chamber and short-axis views. The size and ejection fraction (EF) of the RV and LV were measured by a single observer (WL) by summation of disks methodology. The total RV was divided into a functional RV (from the tricuspid valve (TV) leaflet margins to the pulmonary valve) and an atrialized RV (from the anatomic TV annulus to the TV leaflet margins). Other meas- urements included the degree of TV septal leaflet displacement (expressed as a percentage of the total ventricular septal length), distance of diastolic bowing of the atrialized ventricular septum into the LV, GOS ratio (ratio of the areas of the (right atrium+atrialized RV)/(functional RV+left atrium+LV) measured on 4-chamber view), and cardiothoracic ratio on an axial image. Regression analyses were used to determine the correlation of TV, RV, and LV parameters with ventricular ejection fraction.

\section{Results}

Of the 24 studies identified (age range 0.8 to 54.4 years, median 23.8 years), complete evaluation of the functional $\mathrm{RV}$ was possible in 23. Total RV end-diastolic volume $(\mathrm{EDV})$ and $\mathrm{EF}$ (mean $\pm \mathrm{SD}$ ) were $189 \pm 81 \mathrm{ml} / \mathrm{m}^{2}$ and 44 $\pm 11 \%$. Functional RV EDV and EF were $131 \pm 55 \mathrm{ml} / \mathrm{m}^{2}$ and $45 \pm 13 \%$. Atrialized RV EDV and EF were $59 \pm 39 \mathrm{ml} /$ $\mathrm{m}^{2}$ and $42 \pm 23 \%$. LV EDV and EF were $66+19 \mathrm{ml} / \mathrm{m}^{2}$ and $60 \pm 10 \%$. The percentage of septal leaflet displacement was $50 \pm 16 \%$ and distance of diastolic septal bowing was $0.49 \pm 0.39 \mathrm{~cm}$. Percent septal displacement negatively correlated with functional RV EF ( $\mathrm{p}=0.013$, see Figure 1 ). Percent septal displacement was also negatively correlated with total RV EF ( $\mathrm{p}=0.008)$ but not atrialized RV EF ( $\mathrm{p}=$ $0.20)$. LV EF did not correlate significantly with percent septal displacement, functional or total RV EDV, functional or total RV EF, diastolic bowing, GOS ratio, or cardiothoracic ratio. 


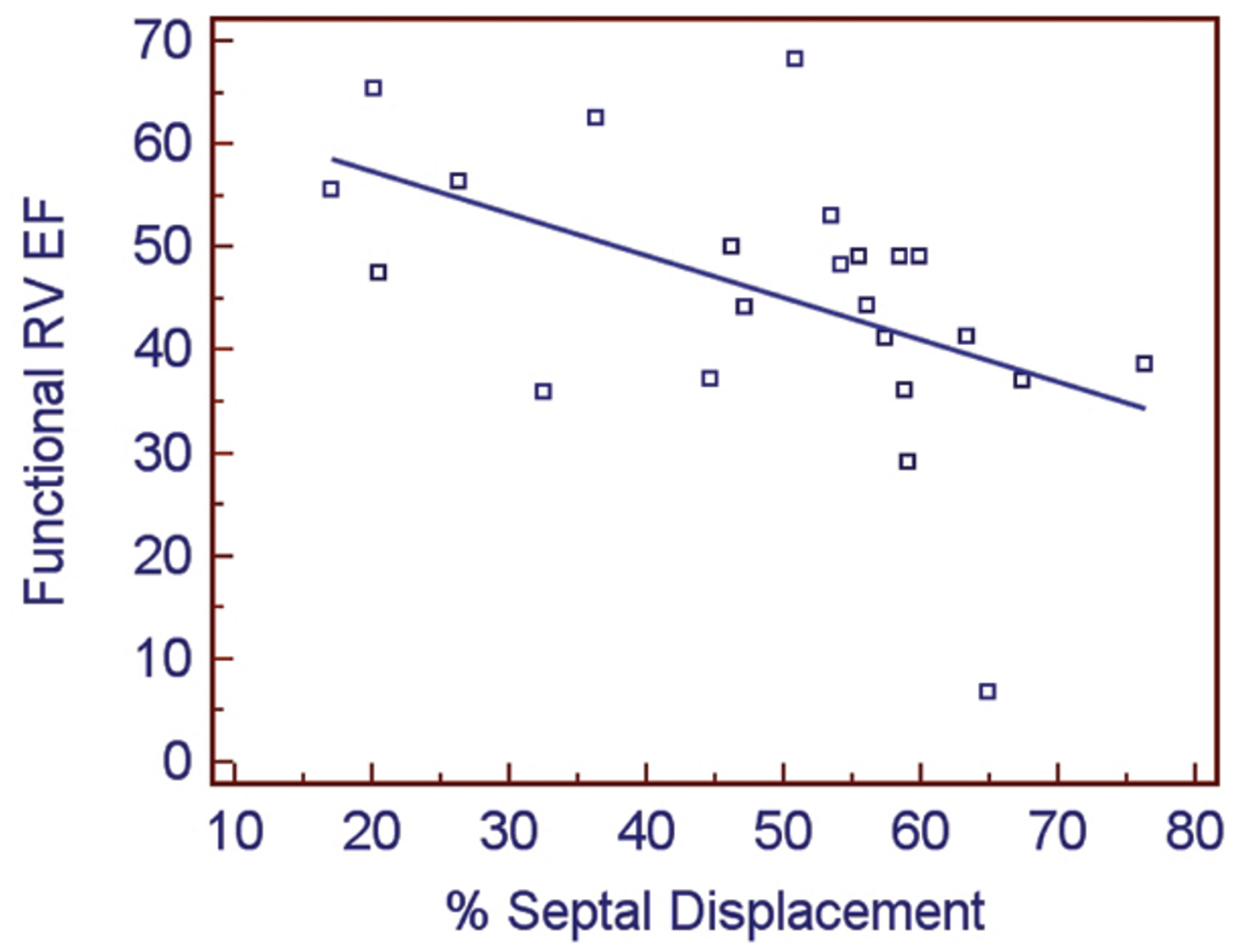

Figure I

Complete evaluation of the functional RV was possible with cardiac MRI in 23 of 24 patients with Ebstein anomaly. Greater tricuspid valve septal leaflet displacement (i.e., less shared ventricular septum) was associated with worse functional RV ejection fraction.

\section{Conclusion}

In patients with Ebstein anomaly, greater septal leaflet apical displacement (i.e., less shared ventricular septum) was associated with worse functional RV ejection fraction. This finding supports the repositioning of the TV annulus in the surgical repair of Ebstein anomaly, which may result in an improvement in the $\mathrm{LV}$ contribution to $\mathrm{RV}$ work.

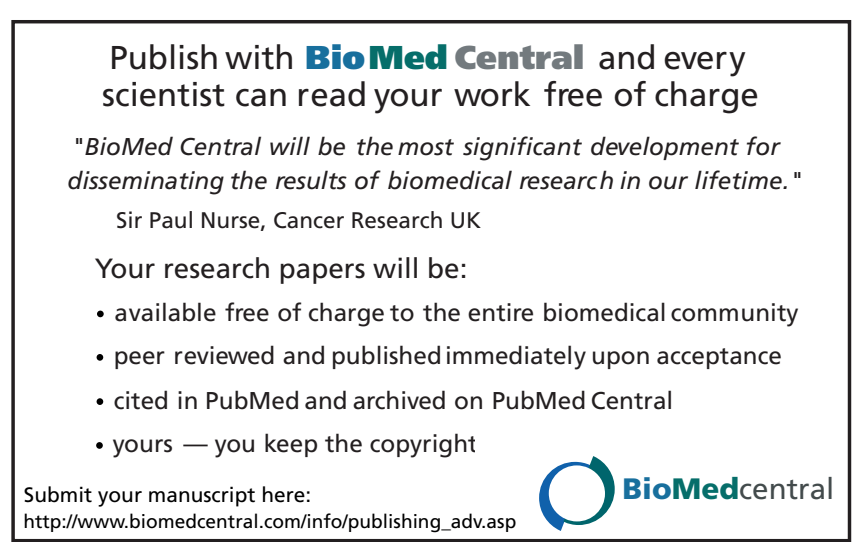

